are helpful and which neutral or potentially harmful. Both studies also demonstrate the value of research in the psycho-social field not only for theoretical purposes but also to ensure that care planning and provision is informed by evidence as well as fashion. It is to be hoped that these 'voices in the wilderness' will be heard.

St James's University Hospital, Leeds

\title{
Demography and Migration
}

\section{Tony Warnes}

\author{
J. A. Brody, Prospects for an ageing population. Nature, 315 (6 June \\ I985), 463-466.
}

As Associate Director for Epidemiology, Demography and Biometry at the USA National Institute of Aging, Jacob Brody has written in this paper authoritative and well-documented reviews of recent improvements in mortality and life expectancy in the United States, of the debate which has arisen on the relationships between life extension and morbidity in later ages, and of the most recent demographic and health forecasts. It begins with some sceptical remarks about Fries's argument that, in the coming decades, there will be little increase in the mean age of deaths but that their variance and negative skew will decrease: otherwise known as the thesis of increasing rectangularity in the survival curve. ${ }^{1}$ To elaborate his view that there is no basis in understanding for this thesis, Brody examines the irregular decrease between I 900 and I 980 of all-age mortality in the United States, from 1,720 to 828 per 100,000. Half of this decrease had occurred by 1920 but, during the same period, mortality among those aged $6_{5}$ and more years declined by only five per cent. The older population was resistant to whatever factors caused the conservation of life in the general population. By about 1945, however, half of the 1900-80 decline in mortality among those aged $6_{5}$ and over had been completed.

Attention is then focused on the period, from 1948 until r 968 , of considerable social, economic and medical advances during which mortality changed little for all ages and actually increased among the elderly. Subsequently, greater economic difficulties notwithstanding, mortality rates have persistently declined, at remarkable rates among the older population. Brody considers the role of a number of medical 
and social interventions in bringing about these irregular and agedifferentiated decreases in mortality, but even when dealing with specific causes of death, such as tuberculosis, he concludes that the inflections along the curves are not understood. In particular, we have very little understanding of why mortality has decreased so rapidly in recent decades. He adds that the recent momentum for life extension seems not to be determined by a decline in cause-specific mortality, but rather to be part of a pattern in which the potential lifespan is ever more closely attained.

The article then examines the sparse national data on trends in health, morbidity and disability. It is argued that there is evidence for a modest gain in healthy years but for far greater increases in the years of compromised physical, mental and social functions. There are no data to establish age-specific declines in deafness, blindness, hip fracture, osteoarthritis or Alzheimer's disease and related disorders. As to less specific indicators of health, following a discussion of the difficulties of measurement and the inadequacy of existing data, it is concluded that there is insufficient information to reach conclusions about whether people are indeed enjoying better health. A brief section then summarises some of the more dramatic age-structure and ill-health projections to the year 2050 which have been published by the US Bureau of the Census. This is done to argue further that those actuarial forecasts which are based on Fries's assumptions, such as those of the Social Security Administration, are misleadingly optimistic and complacent. Arguably it is however a misuse of forecasts to state that unless there are miraculous advances in science and health management in the very near future, there will be an increase in the number with Alzheimer's disease and related disorders from over 2 million to 8.5 million from $\mathrm{I} 980$ to 2050 (my italics).

The main purpose of Brody's article is therefore to argue that 'there is at present no accepted scientific prospect that the net increase in healthy years will exceed the increase of years of dysfunction'. It concludes by discussing whether either health education or research into fundamental biological ageing processes is likely to contribute to the reduction of ill health in advanced age. He says 'the most urgent need is for an understanding of human natural history beyond age 65 , using the emerging data on elderly populations'. Until our present ignorance is displaced, making assumptions with major policy implications is dangerous. When we speculate in good faith, but on a basis of soft data and with projections that human history has already denied, we run the risk of ignoring Hippocrates's basic admonition that 'the physician must be able to tell the antecedents, know the present and foretell the future'. 


\section{NOTE}

I Fries, J. F. and Crapo, L. M. Vitality and Aging: Implications of the Rectangular Curve. Freeman, San Francisco, 198 I. See also Bromley, D. B., Isaacs, B. and Bytheway, W. R., Ageing and the rectangular curve. Ageing and Society, 2 (1982), 383-392.

G. C. Myers and K. G. Manton, Morbidity, disability and mortality: the aging connection, in C. M. Gaitz, G. Niederehe and N. L. Wilson (eds), Aging 2000: Our Health Care Destiny. Springer-Verlag, New York, 1985 , pp. 25-39.

Myers and Manton also begin with reviews of the achieved and forecasted decreases in mortality among the United States population during this century. Both the mean and the variance of the ages of death among those attaining at least 60 years have been increasing in recent years, so 'there has not been a compression of the ages of death at older ages, as would be expected if we were currently near some fixed limit of life expectancy'. Current United States medium variant projections suggest that life expectancy for females will rise to 83.8 years at birth and to 23 . I years at age 65 by the year 2050. If these figures are realised, the average female will live nearly a quarter of her total lifetime after age 65 years.

The authors then examine the trends during this century in the incidence of deaths in association with six diseases, whether reported as the underlying cause or as an element in multiple-cause deaths. There were decreases in the all-age risk of death between 1968 and 1977 from pneumonia and influenza, diabetes, ischaemic heart disease and stroke, but increases from both cancer and chronic respiratory diseases. The same differentiation by disease characterised secondary mentions in multiple-cause deaths. As the declines in the death rates from specific underlying causes have exceeded those of total mentions, it is probable that the duration of diseases has extended and that mortality extensions are occurring not as a result of the elimination of chronic diseases but by reducing their lethal effect at given ages.

A case for the elaboration of the methodology of life-table projections is then made. They argue not only that cause-of-death elimination tables are instructive, but also that projections based on the delay of deaths from specified causes have utility. Estimates are presented of the years added to life expectancy at birth and at 75 years among females in the United States consequent upon the elimination or delay (by various numbers of years) of diabetes and/or stroke. They show that a large fraction of the mortality risk of chronic diseases is in their non-underlying cause occurrences, e.g. the elimination of deaths at all 
ages with diabetes as the prime cause produces an increase of life expectancy of 0.29 years, but the elimination of all occurrences of diabetes increases life expectancy by $0.7 \mathrm{I}$ years.

The relationships between morbidity and mortality in large populations are then addressed. They elaborate an approach developed by Manton and Soldo from models emanating from Nihon University, Japan and the WHO Global Program on Aging. ${ }^{1}$ Their essence is the construction of life tables which represent the age association not only of deaths but also of the onsets of chronic disease and of chronic disability. It is argued that these can be developed readily from survey data, although the problems of definition and of diagnosis are barely discussed. By means of a largely theoretical demonstration, they discuss the potential of these methods for estimating treatment costs, the value of lost wages and other impacts of disease and mortality. Their conclusion is that a fully articulated programme of assessment, capable of generating appropriate forecasts, will require even more sophisticated bioactuarial models, that incorporate interactions between different types of interventions and chronic disease processes. They concur with Brody that there is no clear indication as to which interventions have brought about the steady improvements in the lethality of many of our major chronic diseases, and that there is little understanding about how morbidity and disability gradients have responded to increased longevity.

\section{NOTE}

I Manton, K. G. Changing concepts of morbidity and mortality in the elderly population. Milbank Memorial Fund Quarterly, 60 (1982), $183-244$; Manton, K. G. and Soldo, B. J. A dynamic model of population aging and health status change: implications for the development and implementation of national health policy. Milbank Memorial Fund Quarterly, 63 (1985).

Deborah A. Sullivan, The ties that bind: differentials between seasonal and permanent migrants to retirement communities. Research on Aging, 7 ( 1985$)$, 235-250.

Standard sources can often distort our understanding of social phenomena, and this problem is exemplified in the fields of demography and housing studies. Contemporary trends are eroding the prevalence of such time-honoured and officially measured descriptions as 'fixed place of abode' or 'head of household', and comparable difficulties arise in the study of the migration of the elderly. Spreading affluence, multiple home occupancy, serial monogamy and looser coupling arrangements 
may be cited among the factors that are diluting the relevance of the notion of 'permanent change of residence'. If to date these difficulties are more commonly associated with highly educated, young adults than elderly people, they will soon become a major complication in the residential decisions and mobility of the retired.

Deborah Sullivan has provided one of the first substantial attempts to deal with seasonal migration among the elderly. Her study population is drawn from three contiguous planned retirement communities located twelve miles west of Phoenix, Arizona. It is therefore far from representative of the United States older population, or even of longdistance migrants, but none the less her methodology and her results are of great interest because official sources provide nothing at all on the topic. Of the 55 I respondents from the retirement communities, $\downarrow I$ per cent are classified as permanent residents because they resided twelve months each year at the address. Nine per cent were present for less than half the year and are described as seasonal in-migrants, and twelve per cent were present for between seven and nine months and are described as seasonal out-migrants. The remaining 27 per cent, absent for one or two months, are separately classified, perhaps unnecessarily, as seasonal travellers. Sullivan then investigates the household composition, marital status, age, income, place of origin and family connections of the different groups. She argues forcefully that there is little evidence that seasonal migration is only an intermediate step towards permanent relocation, but finds some evidence that perennial seasonal migration households increase the amount of time that they spend in the retirement community with increasing age.

The only significant differences between seasonal in-migrant and seasonal outmigrant households are that the former are more affluent and more likely to come from small towns and rural areas. Those resident for ten or more months are differentiated from the seasonal migrants by a lower proportion of married couples. They also tend to have lower educational attainment and lower household income. While the seasonal migrants were no less likely to report chronic diseases, they were less likely than year-round residents to regard their health as poor or only fair. There was an inverse relationship between the number of children surviving to the respondents and their annual duration of residence in the retirement communities, and this finding is pursued in an analysis of the differentials between those having children within and beyond a three-hour drive.

Sullivan summarises the factors that inhibit year-round residence. Ties with children and a continuing link with rural and small-town areas of origin, which continue to be regarded as 'home', are important, 
while above-average income and education, an absence of health restrictions on activities and the availability of a partner with whom one can travel, all promote seasonal migrations. The paper is concluded with an extended discussion of the trends in American society which are likely to increase the incidence of seasonal relocations and dual residences. It is an interesting account although little time is spent considering possible contrary influences, and an obvious omission is any reference to the interactions between real incomes and housing supply.

Age Concern Institute of Gerontology, King's College London

Education

Joanna Bornat

Mary Casling, 'The older student: a personal point of view', pp. 231-233; Sydney J. Butler, 'Writing for posterity', Pp. 234-240; Steve Ryan, 'The Open University and older students', pp. 24 I-245; all in Adult Education, vol. $5^{8}$ (3), December 1985 .

Mary Casling retired at sixty and had acquired the degrees of Master of Education and Doctor of Philosophy by the time she was sixty-seven. She provides an older student's insight into the experience of learning at a late stage in life. Her conclusions are that age-segregated classes bring fewer rewards than grouping by interest, that reduced income and physical slowing down need to be compensated for with smaller classes and understanding from tutors and that new technology need hold no fears for older learners. Learning for its own sake brings enjoyment, also skills and knowledge which have spin-off in other areas of life as well as a wider social circle and welcomed opportunities for life review and self knowledge.

Sydney J. Butler describes how a group of 12 women in their sixties and seventies, mainly from professional backgrounds but with little recent experience of writing, took part in a course in 'life-writing' on titled 'Writing for Posterity', at a social centre for senior citizens in Vancouver, Canada. He began with the aim of co-ordinating a group to produce their own booklet, from initial writing, through editing to final publication. With access to a computer the group were able to review each other's work from week to week with supportive criticism. The outcome was a class booklet, 44 pages long, photocopied and stitched in a cardboard cover. 